\title{
Hormonal contraceptive use as risk factor for breast cancer in young Javanese women
}

\author{
Luna Fitria Kusuma ${ }^{1}$, Kristanto Yuli Yarso ${ }^{2}$ \\ ${ }^{1}$ General Surgery Resident of Moewardi Hospital/Sebelas Maret University, Solo, \\ Central Java, Indonesia, ${ }^{2}$ Oncologist Surgeon of Moewardi Hospital/Sebelas \\ Maret University, Solo, Central Java, Indonesia
}

DOI: http://dx.doi.org/10.19106/JMedScieSup0048042016017

\begin{abstract}
Previous study from 351 Indonesian women revealed that they had been diagnosed with breast cancers at younger age compared to Western countries. In this study, we investigated the role of hormonal contraceptive as risk factor for young Indonesian (Javanese) breast cancer patients. However, the presence different lifestyles between ethnics might affect the risk factors across Indonesian populations. Diagnostic and prognostic study findings, including breast cancer prediction rules, must therefore be validated in Asian women. We undertook casecontrol study to determine population-based distributions of breast cancer among young Javanese people, one of the largest populations in Indonesia (Southeast Asia). A total of 500 women diagnosed with breast cancer participated in this study, divided in to two groups: young (less than 40 years old) and mature breast cancer patients. Data for hormonal contraceptive, clinicopathological characteristics, and other risk factors were collected. Our study found that young Javanese women with history of using hormonal contraceptive for more than 10 years had 4.67-fold increased risk of being diagnosed with breast cancer in younger age $(p<0.01)$. There was no difference between these two groups in menarche and parity. Interestingly, for Javanese women who breastfeed their babies for more than 18 months had 1.74-fold increased risk of being diagnosed with breast cancer in younger age $(p<0.01)$.
\end{abstract}

Keywords: breast cancer; younger age; hormonal contraceptive; Indonesia 